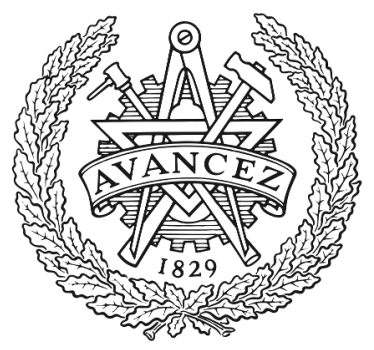

CHALMERS

UNIVERSITY OF TECHNOLOGY

\title{
Spatial analysis of urban material stock with clustering algorithms: A Northern European case study
}

Downloaded from: https://research.chalmers.se, 2023-04-26 02:49 UTC

Citation for the original published paper (version of record):

Gontia, P., Thuvander, L., Ebrahimi, B. et al (2019). Spatial analysis of urban material stock with clustering algorithms: A Northern European case study. Journal of Industrial Ecology, 23(6): 1328-1343. http://dx.doi.org/10.1111/jiec.12939

N.B. When citing this work, cite the original published paper. 


\section{Spatial analysis of urban material stock with clustering algorithms}

\section{A Northern European case study}

\section{Paul Gontia (D) | Liane Thuvander | Babak Ebrahimi (D) | Victor Vinas \\ Leonardo Rosado | Holger Wallbaum}

Department of Architecture and Civil Engineering, Chalmers University of Technology, Gothenburg, Sweden

Correspondence

Paul Gontia, Department of Architecture and Civil Engineering, Chalmers University of Technology, 6 Sven Hultins, 4th floor Goteborg 412 96, Sweden.

Email:paulgo@chalmers.se, paulgontia @yahoo.com

\section{Funding information}

Mistra Urban Futures; Svenska Forskningsrådet Formas

Editor Managing Review: Claudia Binder

\begin{abstract}
A large share of construction material stock (MS) accumulates in urban built environments. To attain a more sustainable use of resources, knowledge about the spatial distribution of urban MS is needed. In this article, an innovative spatial analysis approach to urban MS is proposed. Within this scope, MS indicators are defined at neighborhood level and clustered with $k$-mean algorithms. The MS is estimated bottom-up with (a) material-intensity coefficients and (b) spatial data for three built environment components: buildings, road transportation, and pipes, using seven material categories. The city of Gothenburg, Sweden is used as a case study. Moreover, being the first case study in Northern Europe, the results are explored through various aspects (material composition, age distribution, material density), and, finally, contrasted on a per capita basis with other studies worldwide.

The stock is estimated at circa 84 million metric tons. Buildings account for $73 \%$ of the stock, road transport $26 \%$, and pipes $1 \%$. Mineral-binding materials take the largest share of the stock, followed by aggregates, brick, asphalt, steel, and wood. Per capita, the MS is estimated at 153 metric tons; 62 metric tons are residential, which, in an international context, is a medium estimate. Denser neighborhoods with a mix of nonresidential and residential buildings have a lower proportion of MS in roads and pipes than low-density single-family residential neighborhoods. Furthermore, single-family residential neighborhoods cluster in mixed-age classes and show the largest content of wood. Multifamily buildings cluster in three distinct age classes, and each represent a specific material composition of brick, mineral binding, and steel. Future work should focus on megacities and contrasting multiple urban areas and, methodologically, should concentrate on algorithms, MS indicators, and spatial divisions of urban stock.
\end{abstract}

KEYWORDS

bottom-up method, built environment, construction materials, geospatial data, material intensity, urban form

\section{1 | INTRODUCTION}

Construction materials comprise the largest material stock (MS) accumulated in modern society. During the last century, MS increased 23-fold worldwide (Krausmann et al., 2017). Even though specific nations show distinctive accumulation patterns, the speed of material accumulation is accelerating globally (Fishman, Schandl, \& Tanikawa, 2016). The unprecedented growth of stock is directly linked to high resource consumption, demolition waste discharges, and global and local environmental impacts (Fischer-Kowalski et al., 2011; Wiedenhofer, Steinberger, Eisenmenger, \& Haas, 2015). 
Materials accumulated in society can, nevertheless, be viewed as repositories of anthropogenic resources for the economic system. To be sustainable, the economic system should function similarly to ecosystems, in which resources are transformed almost indefinitely with minimum waste and no related environmental impacts. Compared to primary resources, anthropogenic resources have received less attention in research and, accordingly, are very little understood. Therefore, knowledge regarding the accumulated MS (mass and volume, material composition, age, and density of the stock) and its dynamics (spatial expansion, speed of accumulation, and density increase) is needed.

Several MS methods have been developed in the field of industrial ecology. Tanikawa, Fishman, Okuoka, and Sugimoto (2015) have distinguished four method types, based on the approach and the interrelated data used: bottom-up accounting, top-down accounting, demand-driven modeling, and remote sensing approaches. Augiseau and Barles (2017) have considered a temporal dynamic dimension (in use, retrospective, and prospective) and distinguished between stock- and flow-driven modeling. In relation to stock modeling, the authors have differentiated three methods: bottomup stock analysis, top-down prospective, and top-down retrospective stock analysis using a flow-driven model.

Construction materials accumulate in multiple components of the built environment such as buildings, road, and railroad transportation networks, drinking water and wastewater pipes, and gas pipe networks. In previous research, MS has been estimated for single or multiple components of the built environment. For instance, Guo, Hu, Zhang, Huang, and Xiao (2014), in the case of Beijing, and Nguyen, Fishman, Miatto, and Tanikawa (2018), in the case of Vietnam, have investigated road networks only, and Kleemann, Lederer, Rechberger, and Fellner (2016), in the case of Vienna, and Ortlepp, Gruhler, and Schiller (2015), in the case of Germany, have investigated buildings only. The studies that have examined multiple components of the built environment (Han \& Xiang, 2013; Huang, Han, \& Chen, 2016; Tanikawa \& Hashimoto, 2009; Tanikawa et al., 2015; Wiedenhofer et al., 2015) have indicated that the largest stock is accumulated in buildings that takes between 43 and $90 \%$ of the total MS depending on which and how many of the built environment components are analyzed. This could explain why most of the studies in the field focus on buildings (Kleemann et al., 2016; Mesta, Kahhat, \& Santa-Cruz, 2018; Reyna \& Chester, 2015). The proportion of the stock among other infrastructure types is not as straightforward. For example, in the case of Japan, the road network makes the second largest contribution to the overall MS (Tanikawa et al., 2015); for the largest three cities in China, the pipes network is the second highest contributing infrastructure to MS (Huang et al., 2016).

Studies on MS have been carried out on diverse spatial scales, ranging from an urban neighborhood to multiple countries. For instance, Tanikawa and Hashimoto (2009) have estimated the stock for centrally located districts of Manchester in the United Kingdom and Wakayama in Japan. A few studies have focused on a country's prefectures (Fishman, Schandl, \& Tanikawa, 2015; Han \& Xiang, 2013) and others on multiple countries (Fishman et al., 2016; Fishman, Schandl, Tanikawa, Walker, \& Krausmann, 2014; Wiedenhofer et al., 2015). Urban areas have received the most attention (Guo et al., 2014; Huang et al., 2016; Kleemann et al., 2016; Mesta et al., 2018; Reyna \& Chester, 2015), which can be explained by the rapid urbanization trends at a global level (United Nations, 2014).

Urban MS has been analyzed from multiple spatial perspectives. Kleemann et al. (2016), in the case of Vienna, have estimated the stock in buildings and emphasized the need for spatial analysis in the field. The authors have used density (mass per built-up area) to indicate the spatial distribution of material composition and intensity. Reyna and Chester (2015), in the case of Los Angeles, have estimated the historical expansion of building stock, construction materials accumulated, and their embodied environmental impacts. In this case, the authors have used density in mass per land area to indicate the spatial variations of MS. Han et al. (2018), in the case of Shanghai, have uncovered the spatiotemporal dynamics of MS in multiple infrastructures. The authors have used a spatial-resolution grid of 500 meters and have delineated three distinct urban areas (center, periurban, and suburban) to spatially indicate MS dynamics. In spite of this progress, there are matters that are currently less understood such as the following: how material composition in the accumulated stock varies spatially, how it relates to the characteristics of the in-use stock (e.g., age, building type, etc.), and whether more refined spacial patterns can be depicted in the urban geography.

Furthermore, with a few exceptions, MS relations to urban form have not been addressed in the research literature. Schiller (2007) has used urban form typologies to model the long-term material flows needed to maintain and expand the stock of residential buildings in Germany. The author has demonstrated that (a) low-density residential areas have a higher share of MS in infrastructure networks and (b) long-term inflows of materials related to maintenance of infrastructure networks are higher than the inflows related to maintenance and expansion of residential buildings. Han et al. (2018) have underlined an increase in MS utility (on a per capita basis) in more compact urban forms. However, the apparent material gain comes with a tradeoff. Contemporary compact urban forms have a larger share of high-embodied environmental-impact construction materials such as steel and concrete. Even though one of the studies has used a theoretical description of urban form and the other has statistically analyzed the urban form of an urban case study, further work on MS related to urban form and new approaches to spatially analyzing them are needed. For instance, questions such as how to identify MS patterns in relation to urban form and to indicate those patterns spatially have not yet been addressed.

In the present study, in-use MS was estimated with a bottom-up method for an urban area. The estimate was created with (a) material-intensity coefficients and (b) spatial data for three built environment components: buildings, road transportation, and pipes. The main contribution of this article to MS field is twofold:

- An innovative approach for spatial analysis of urban MS is introduced. The main scope is to identify urban areas that have similar MS characteristics, which can then be displayed on maps for spatial interpretation. For this purpose, neighborhoods' administrative boundaries were used to capture urban areas with different characteristics. At the neighborhood level, two sets of MS indicators were defined and then clustered with 


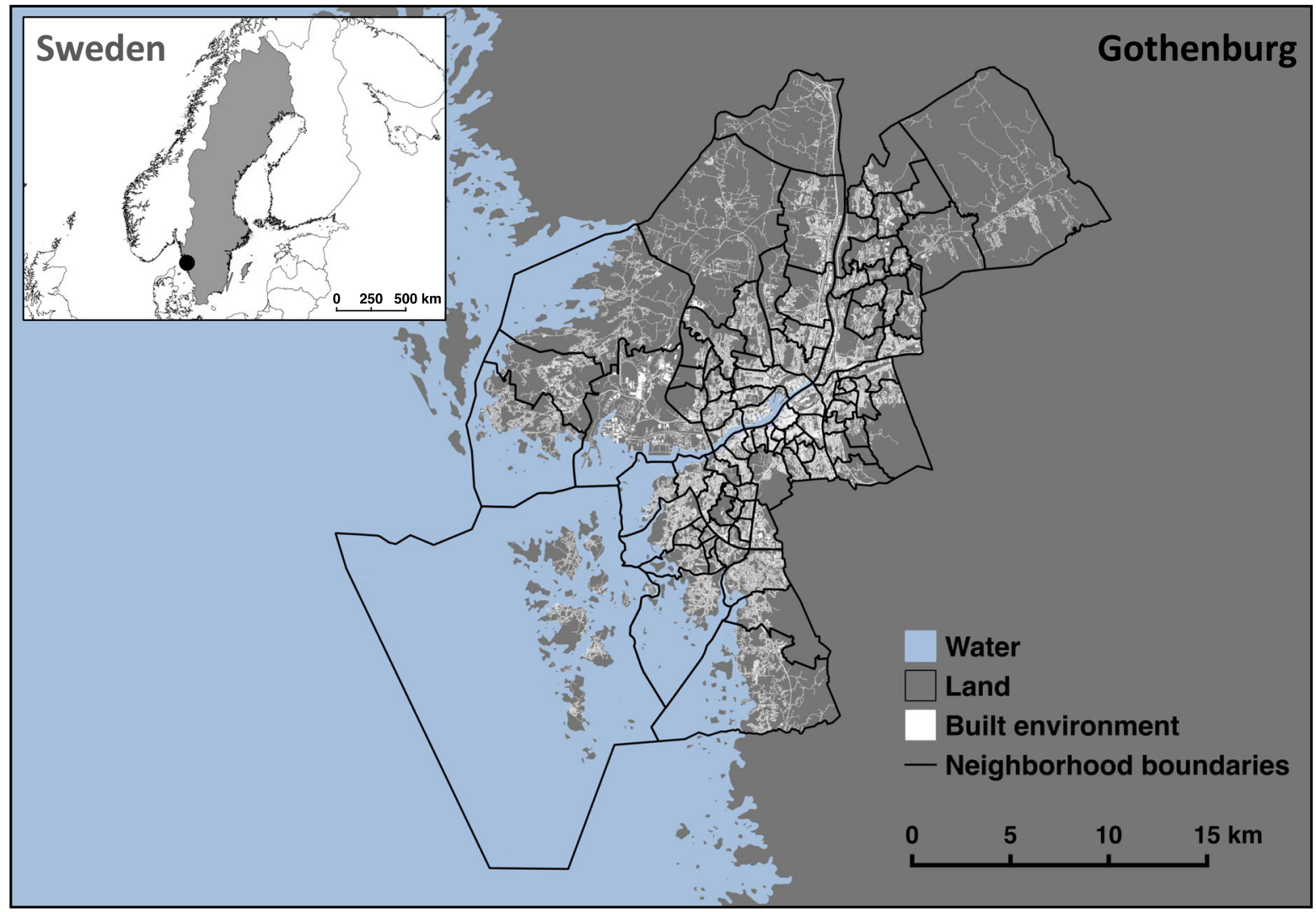

FIG URE 1 Geographical location of Gothenburg city in Sweden, the administrative boundaries of the 96 neighborhoods, and built environment spatial distribution

k-mean algorithms. With the defined indicators (a) relations between urban form and MS in-built environment components, and (b) spatial differences in MS composition were underlined. Some of the above-mentioned research gaps were addressed through this analytical approach. It must be noted that the approach proposed in this work is not intended to substitute other spatial and statistical methods previously employed in the field, but to complement them.

- The present study is the first of its kind in Northern Europe. Therefore, the results were explored from a variety of perspectives (material composition, age distribution, and material density) and, finally, contrasted on a per capita basis to the other case studies worldwide.

\section{1 | The case study}

The city of Gothenburg is located on the west coast of Sweden (Figure 1). It is the second largest city in the country with an area of $447 \mathrm{~km}^{2}$ and approximately 560,000 residents in 2016 (Statistics Gothenburg, 2016a). The city has a diverse economy and accommodates the largest port in Northern Europe. It is also culturally diverse with a high yearly inflow and outflow of inhabitants (Statistics Gothenburg, 2016a).

The subcity administrative boundaries of Gothenburg have changed over time (Statistics Gothenburg, 2018a) and currently are divided at three levels: 10 large districts, which are divided into 96 neighborhoods, which are finally segmented into 900 smaller base areas (Statistics Gothenburg, 2018b). For this study, the boundaries of the 96 neighborhoods were chosen, and are shown in Figure 1.

\section{2 | METHODS AND MATERIALS}

The estimation of MS was created with a bottom-up method. Two dataset types were used in the modeling process: material-intensity coefficients and spatial data. To spatially analyze the urban MS, two sets of indicators were defined at neighborhood level and clustered with $k$-mean algorithms.

\section{1 | Bottom-up MS}

Equation (1) is a simplified mathematical representation of the MS modeling. Material-intensity coefficients specific to each built environment component were multiplied with the corresponding physical size (area or length) measured within the spatial boundaries of the case study. MS was 
calculated for the following built environment components: buildings, road transportation, and pipes. Classes were defined for each component (e.g., age, building types, and function, etc.) and are introduced in detail in the text below. Seven material categories were considered for the results presentation: wood-based materials, ceramics and brick, mineral-binding materials, stone and aggregates, iron and steel, asphalt, and others (e.g., glass, polymers, etc.). Since a standardized nomenclature of construction materials and their classification into categories is not yet available, these seven material categories were defined to fit the categories used in previous studies as far as possible (Krausmann et al., 2017; Tanikawa et al., 2015).

$$
\mathrm{MS}_{i, n, m}=\sum X_{i, n, m} \times B_{n, m}
$$

where $\mathrm{MS}_{i, n, m}$ is the material stock for the material category $i$, for component $n$, class $m ; X_{i, n, m}$ is the intensity of material category $i$, for the component $n$, class $m$; and $B_{n, m}$ is the physical size of component $n$, class $m$.

\section{2 | Datasets}

\subsection{1 | Material-intensity coefficients}

The material-intensity coefficients for the three components considered are shown in Table 1. For residential buildings, the coefficients were collected from an earlier study (Gontia, Nägeli, Rosado, Kalmykova, \& Österbring, 2018). Both single-family (SF) and multifamily (MF) residential buildings were included and further separated into four age classes (Table 1). Nonresidential buildings are divided by their function in society into economic, industrial, and public, and further separated into age classes (Table 1). The age classes were defined thorough observations of 50 architectural drawings of nonresidential buildings dating from 1880 to 2010. The architectural drawings were collected from the archives of the city planning authority (Stadsbyggnadskontoret, 2018). The main criteria used for the age class segmentation was the type of construction material used in a building's structure. The material-intensity coefficients were calculated for 15 of the most representative buildings with the volume of construction materials and the corresponding densities.

The road transportation network was separated into roads and bike lanes. Based on average annual daily traffic (AADT) criterion, the roads were further separated into three standard intervals: lower than 3,500, 3,501-6,000, and higher than 6,000 vehicles per day. Bike lanes are built in a single standard dimension and, therefore, only one coefficient was defined (Table 1). The coefficients for road transportation were derived from the literature (Mirzanamadi, Hagentoft, Johansson, \& Johnsson, 2018b; Mirzanamadi, Johansson, \& Grammatikos, 2018a) and supported by the findings of road-infrastructure experts and researchers.

The pipe network was separated into two different systems: drinking water and wastewater. The material-intensity coefficients were calculated for 275 pipe types, and are shown, aggregated in age classes and two diameter intervals, in Table 1. To derive the coefficients, the volumes were related to mass with material density. The volume was calculated for one linear meter and from the differential area of the interior and exterior diameter of the pipe. Secondary data were mainly used for the pipes' coefficients. The largest share of the data was taken from Malm et al. (2011) and was further complemented with reports from manufacturers, which follow the Swedish national standards. For example, the report published by Pipelife Sverige AB (2000) was used to extract the diameters of the polyethylene pipes.

\subsection{2 | Spatial data}

Area and length of the three built environment components were derived from spatial data and are shown aggregated for Gothenburg city, in Table 2. The spatial data were collected for the year 2016.

For buildings, four spatial datasets were used: polygon, height, function, and year of construction. To estimate the in-use gross floor area, the area of the building footprint was multiplied by the number of floors. The footprint area was determined from the polygon features of each building object. The number of floors was derived from the building's height divided by the average height of a single floor. A building's function and year of construction were used to match the spatial data with the corresponding material-intensity coefficients. Residential buildings were separated into SF and MF, and nonresidential buildings were separated into economic, industrial, and public (Table 1). Year of construction of each object was used to form the age classes as shown in Table 1. Building features were merged in QGIS software (QGIS Development Team, 2018). If the dataset was georeferenced, the QGIS function "Join attributes by location" was used. If the dataset was not georeferenced, the features were joined to the spatial data, based on the identification code of each building object.

The spatial datasets for buildings were collected from three different authorities described below. Whenever the data were incomplete, assumptions were made. Polygon geodata were collected from the Swedish National Land Survey (Lantmäteriet, 2018) for 84,600 building objects. Heights of buildings were collected from the city planning authority (Stadsbyggnadskontoret, 2018) and matched $92 \%$ of the building objects. For the remaining $8 \%$, an average height was assumed depending on the building function. Spatial data for the function of buildings were collected from the Swedish National Land Survey (Lantmäteriet, 2018) and available for all the objects. Year of construction data were collected from the Building Register at the Swedish National Land Survey (Lantmäteriet, 2018) for $80 \%$ of the objects. The remaining $20 \%$ of the stock was assumed to have the same age distribution as the $80 \%$ for which the year of construction data were available. 
TAB LE 1 Material-intensity coefficients for the three built environment components

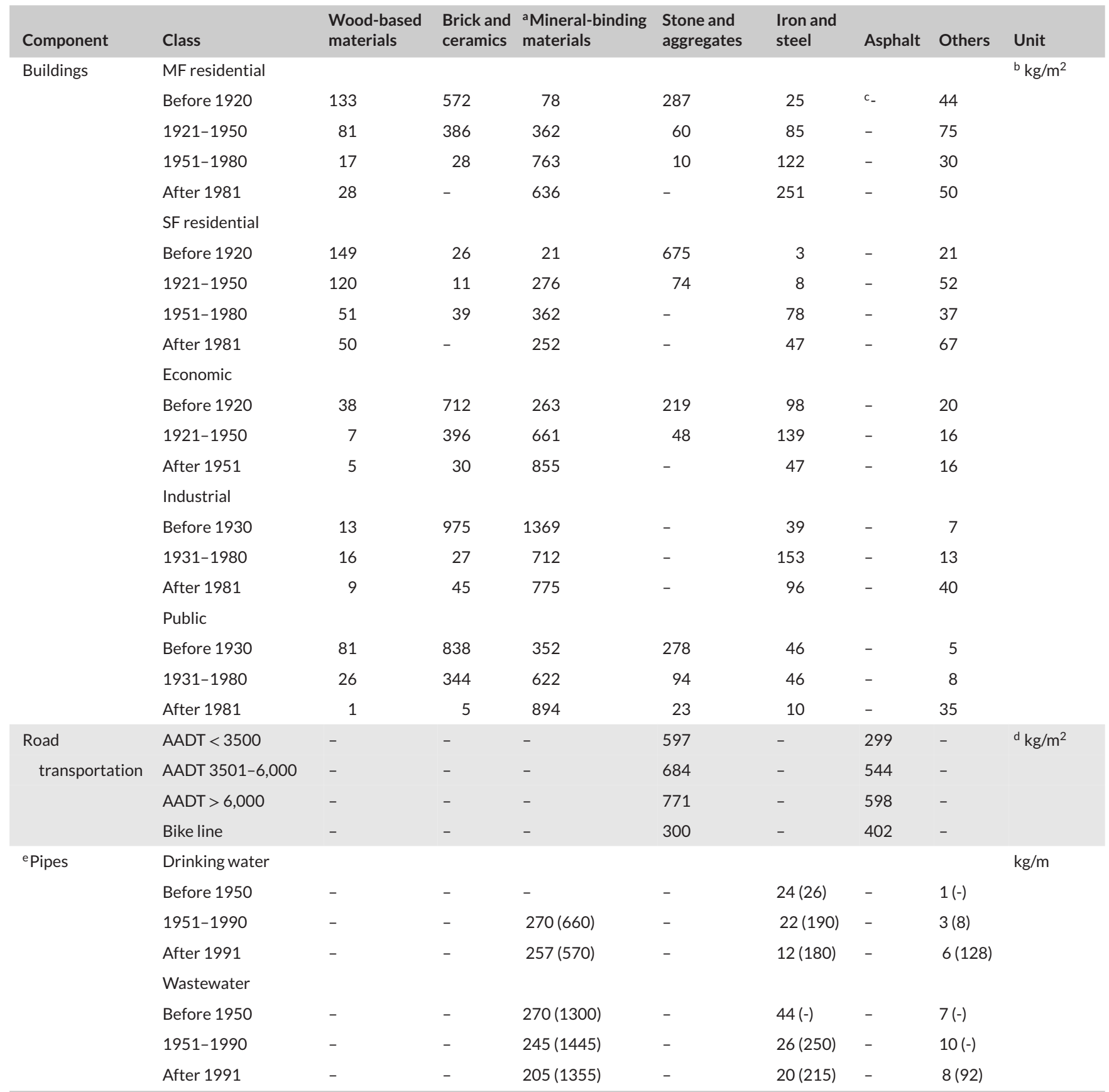

AADT, average annual daily traffic; MF, multifamily residential buildings; SF, single-family residential buildings.

${ }^{a}$ Concrete cement is part of mineral-binding material category. An extended list of the construction materials and their classification into categories can be found at Gontia et al. (2018). Note that the six material categories shown in the mentioned article are complemented here with asphalt material category. That is because road transportation has high composition of asphalt.

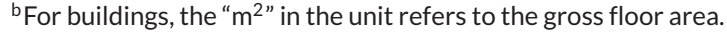

'The sign indicates: not applicable for the described category.

"For road transportation, the " $\mathrm{m}^{2}$ " in the unit refers to the area at the ground level.

e Material-intensity coefficients for pipes are shown in two intervals of diameters: $<800 \mathrm{~mm}$ and $\geq 800 \mathrm{~mm}$. The second interval is displayed in parentheses. When not applicable for the interval, this is marked with "-." 
TA B LE 2 Area and length of the three built environment components for Gothenburg city

\begin{tabular}{llll} 
Component & Class & Area and length & Unit \\
Buildings & Multifamily residential & $22.7 \times 10^{9}$ & $13.8 \times 10^{9}$ \\
& Single-family residential & $8.9 \times 10^{9}$ \\
& Economic & $7.5 \times 10^{9}$ \\
& Industrial & $9.4 \times 10^{9}$ \\
\hline Road transportation & Public & $3.9 \times 10^{3}$ \\
& AADT $<3500$ & $9.6 \times 10^{3}$ \\
\hline Pipes & AADT 3501-6000 & $4.1 \times 10^{3}$ \\
& AADT $>6000$ & $1.4 \times 10^{3}$ \\
\hline
\end{tabular}

AADT, average annual daily traffic.

${ }^{\text {a }}$ Refers to the entire gross floor area currently accumulated in building stock.

${ }^{\mathrm{b}}$ Refers to the area at the ground level of the road, which was calculated with the length and width of the road.

The areas for the roads and bike lanes were calculated by multiplying the length with the equivalent width. The width for roads differs depending on the AADT class and, therefore, this attribute was taken into consideration. Similarly, the length of road was estimated separately for each of the three ADDT classes. Terrain elevation features were taken into consideration for an appropriate estimation of the length. The surface materials (e.g., bedrock, clay, etc.) on which the roads are constructed further influence the thickness of the transversal layers (e.g., wearing, base, etc.). Therefore, this feature was attributed to the road transportation networks and these specifications were considered when modeling the stock. Planning data, which indicate the year of land developed, were used to assign the year of construction for the roads. The spatial data used for road transportation were entirely georeferenced, and, therefore, these attributes were joined by location. The length and ADDT data were collected from the Swedish Transport Administration (Trafikverket, 2018). The surface materials, elevation, and planning data were obtained from the Swedish National Land Survey (Lantmäteriet, 2018). Planning data and the derived years of construction matched $82 \%$ of the road network. For all the other features, the data matched entirely.

Circa 12,500 segments of pipes of different lengths were modeled. The following features were attributed to each pipe segment: length, material type, diameter, year of installation, and system type (drinking water or wastewater). Apart from the year of installation, which was used to indicate the age distribution of MS, these features were used to match the material-intensity coefficients of 275 pipe types with the spatial data. The spatial data were collected for $100 \%$ of the in-use pipes stock from the municipal water management office in Gothenburg (Kretslopp och Vatten, 2018). For confidentiality reasons, the data were provided in Excel files based on the authors' specifications, and no other spatial analysis was performed.

\section{3 | Spatial analysis: Clustering algorithms and indicators}

The spatial analysis approach introduced here is an attachment to the bottom-up MS estimates. The main scope of this approach is to identify urban areas that have similar MS characteristics, which can then be displayed on maps for spatial interpretation. To capture the characteristics of different urban areas, neighborhood administrative boundaries were utilized. In the case of Gothenburg, the 96 neighborhood boundaries (Statistics Gothenburg 2018b) were used. To divide the entire urban stock, neighborhood identification codes were attached to the build environment components with the GIS function "Join attributes by location." At this spatial level, two sets of MS indicators were defined. Their description is presented below and the inventory of the data can be found in Supporting Information S1.

The first set of indicators was used to underline relations between MS and urban forms. The indicators used are:

- MS density (mass per land area) separated by built environment components: buildings, road transportation, and pipes.

- Building types: residential and nonresidential.

- Residential building types: SF and MF. Note that the indicator is derived from number of buildings.

The second set of indicators was used to underline spatial differences in material composition of the stock. The analysis was carried out for residential buildings, using the further mentioned indicators. Nonresidential buildings (building types: economic, industrial, and public) were also tested in a similar way and the results are considered in Section 4.

- MS separated by material category: wood-based materials, ceramics and brick, mineral-binding materials, stone and aggregates, iron and steel, and other. Note that asphalt was not regarded as a separate material category because it has a low share in residential buildings. 
- Residential building type: SF and MF. Note that the indicator is derived from gross floor area.

- Age class: before 1950, 1951-1980, and after 1981.

Next, the indicators were standardized and clustered with k-mean algorithms (Hartigan \& Wong, 1979). Clustering analysis is an unsupervised learning technique, used to partition a set of unclassified observations into homogenous subgroups. The optimal number of clusters was determined with the elbow method (Tibshirani et al., 2001), which indicates the point at which the improvement in error decreases sharply with any additional increase in the numbers of clusters. The derived clusters were assigned back to the 96 neighborhoods to form new maps for spatial interpretation. To test if a different algorithm leads to different results, hierarchical clustering (Murtagh, 1985) and k-median clustering (Cardot, Cénac, \& Monnez, 2012) were employed for the second set of indicators. The results are considered in the Section 4.

\section{3 | RESULTS}

\section{1 | Urban MS in a Northern European case study}

The in-use MS for Gothenburg city is estimated at 84 million metric tons ( $t$ ) and the per capita to $153 \mathrm{t}$. Of the total stock, mineral-binding materials (48\%) take the largest share, followed by stone and aggregates (20\%), ceramics and brick (10\%), and asphalt ( $9 \%$ ). Steel takes circa $7 \%$ of the stock and wood-based materials equate to $3 \%$ (Figure 2). The majority of the MS can be found in buildings (73\%), followed by road transportation (26\%) and pipes (1\%) (Figure 2). For the building stock, residential buildings accommodate $56 \%$ and nonresidential buildings $44 \%$ of the MS. Residential MF buildings take $67 \%$ and SF take 33\%. Within the nonresidential buildings, each function type contributes with circa one third: economic (36\%), industrial (28\%), public (37\%). For the transportation stock, roads take $95 \%$ and bike lanes $5 \%$. From the pipes' stock, drinking water takes $7 \%$ and wastewater $93 \%$.

\subsubsection{Age and material composition of the stock}

In Figure 2a, the age distribution of the in-use MS is shown. It can be seen that the largest part of the stock (circa 40\%) dates to 1960 s and 1970 s. The high stock dating to this period is explained by the national initiative of 1965 , when it was proposed to build one million apartments within one decade (Boverket 2014). Even though the national program was intended solely for residential buildings, nonresidential buildings and the network infrastructures also demonstrate the highest stock dating to this period. Only $3 \%$ of the stock dates to before 1920 . The other decades show a contribution of an average $8 \%$. Figure $2 \mathrm{~b}$ shows the material composition of the in-use stock in relation to the construction period. On average, $50 \%$ of the stock prior to 1920 s consists of stone and aggregate, followed by brick and ceramics (26\%). From the 1920 s onwards, mineralbinding materials show the largest contribution to MS, which is, on average, 50\%. Until 1960, brick and ceramics constitute a considerable share of the stock (average 27\%). Wood-based materials show a decreasing contribution from $7 \%$ for the older stock to $2 \%$ for the more recently accumulated stock. On the contrary, steel and asphalt show an increased contribution with time, from 4 to $8 \%$ and from 5 to $11 \%$, respectively. Figure $2 c$ shows the in-use stock in different built environment components in relation to the construction period. It can be seen that, regardless of the decade interval, the largest share of in-use stock is in the buildings. However, the results also demonstrated that the share of road transportation grew in proportion with time. Pipes resemble the fluctuations shown by road transportation, but do not show an increasing contribution to MS with time.

\subsection{2 | Density of material stock}

Figure 3 shows the density of the stock, in-mass per land area, for the three component types, but only for a few selected material categories. The 96 neighborhoods have been used to spatially illustrate the stock density. It can be seen that the largest density is in buildings for mineral-binding materials (up to $1,550 \mathrm{~kg} / \mathrm{m}^{2}$ ), followed by brick and ceramics (up to $700 \mathrm{~kg} / \mathrm{m}^{2}$ ), and wood-based materials (up to $120 \mathrm{~kg} / \mathrm{m}^{2}$ ). A lower density is evident for asphalt in road transportation, which shows results of up to $75 \mathrm{~kg} / \mathrm{m}^{2}$, and, finally, steel in the pipes network has less than $1 \mathrm{~kg} / \mathrm{m}^{2}$. In regard to the spatial distribution, it can be seen that the highest stock density is in the centrally located areas. Further away from the center, toward the outskirts of the city, the material density decreases. This is because the land has been built up at different intensities. Aspects, such as heights of buildings, building types, and age of the stock further influence the materials density and its spatial distribution. For instance, brick and ceramics category is highly concentrated in the city center (Figure 3). The centrally located areas are characterized by the largest share of MF buildings erected before 1950, which have the highest brick and ceramics material intensity (Table 1). Mineral-binding and wood-based material categories have a relatively high stock density in the intermediary areas of the city (Figure 3 ). These areas are characterized, in the case of mineral-binding materials, by the buildings from 1960s and 1970s, which have the highest mineral-bindings material intensity. In the case of wood-based materials, the intermediary areas are characterized by SF residential buildings, which have the highest wood-based material intensity. Steel in pipes shows a less centered spatial distribution, which can be explained by the fact that steel pipes are no longer in use and have mainly been replaced by plastic pipes from the 1970 s onwards. The results only indicate the remaining in-use stock. 


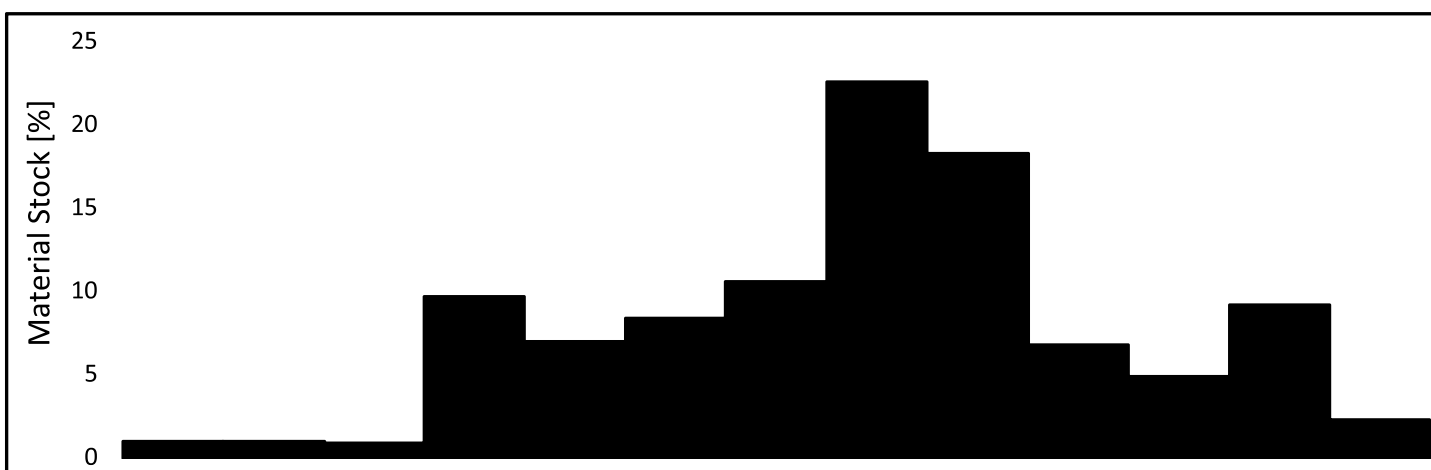

(a)
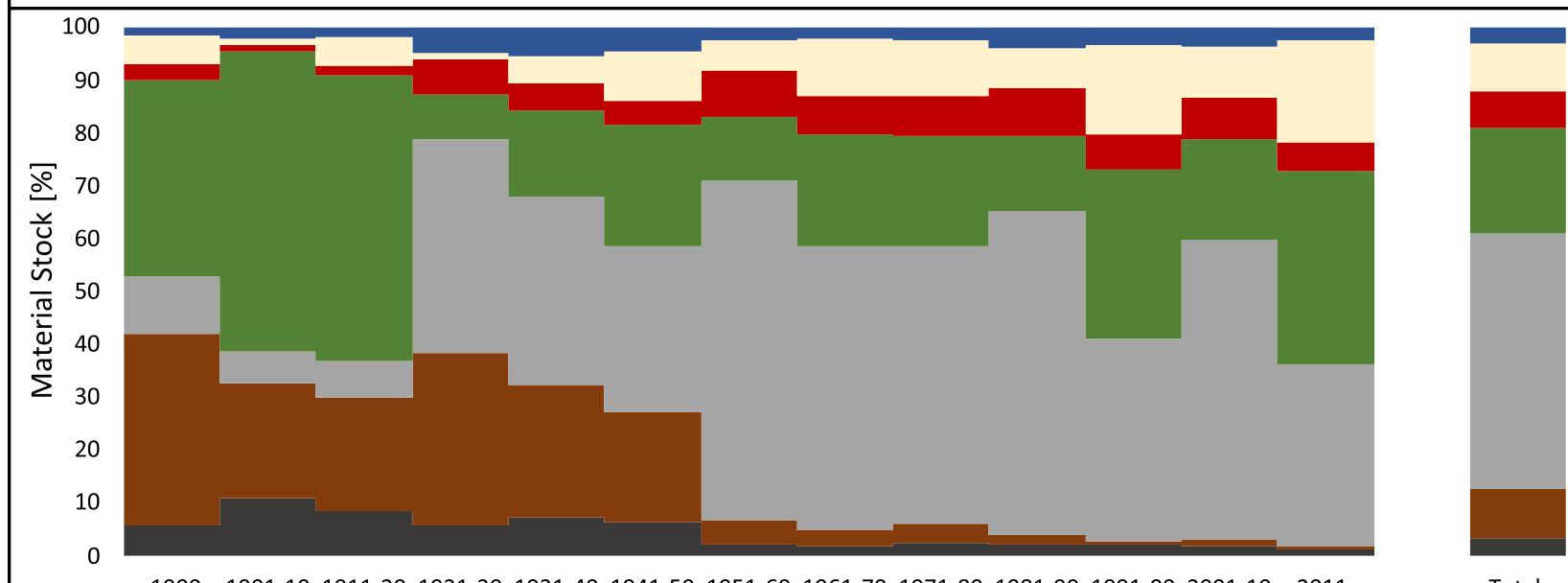

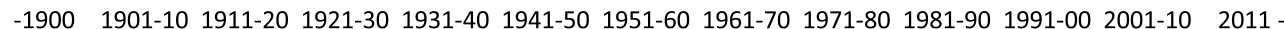

Wood-based materials

- Iron and steel

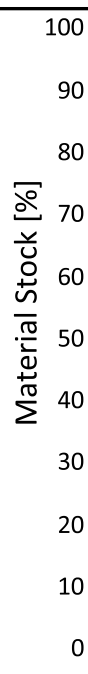

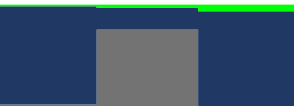

80

0
- Brick and ceramics

Asphalt

-1900 1901-10 1911-20 1921-30 1931-40 1941-50 1951-60 1961-70 1971-80 1981-90 1991-00 2001-10 2011 -

- Buildings
Mineral-binding materials $\square$ Stone and aggregates

ather

(b)

FIGURE 2 Material stock characteristics in the City of Gothenburg. (a) In-use stock by decade from before 1900 until after 2011 shown as percentages derived from mass; (b) material composition from before 1900 until after 2011 shown as percentages derived from mass; (c) material stock by built environment component from before 1900 until after 2011 shown as percentages derived from mass. The last bar in graphs (b) and (c) represent the characteristics of the total in-use material stock as of 2016. Additional data provided in Supporting Information S2 
(a) Buildings
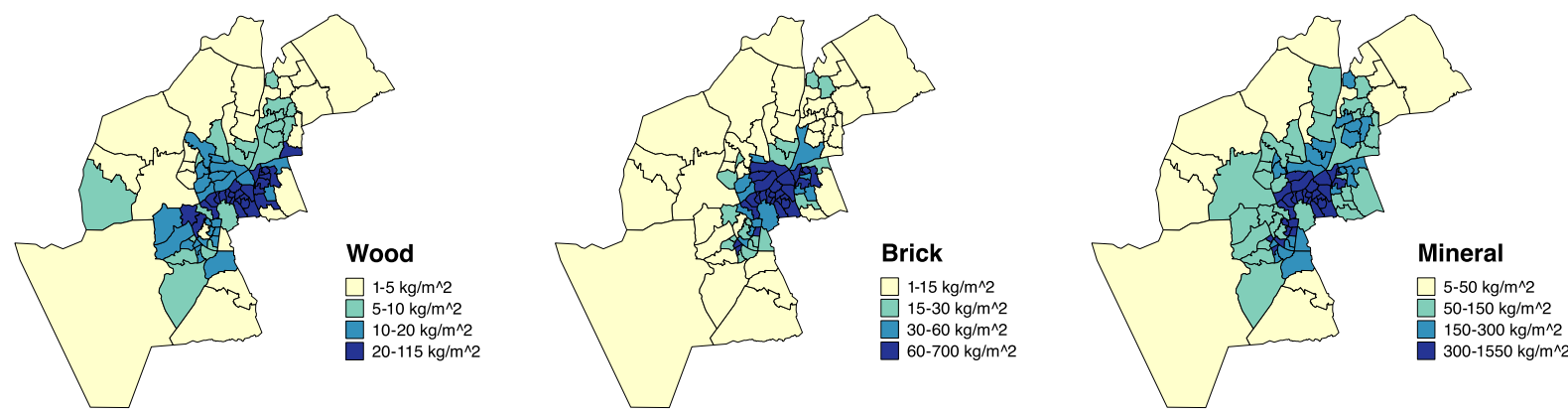

(b) Road transportation

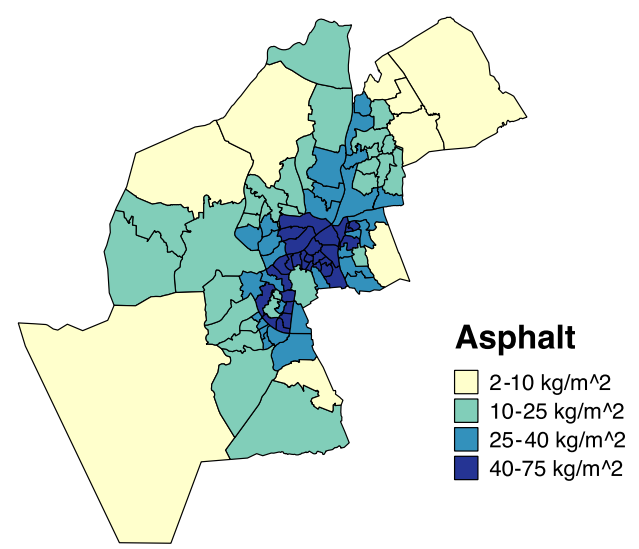

(c) Pipes

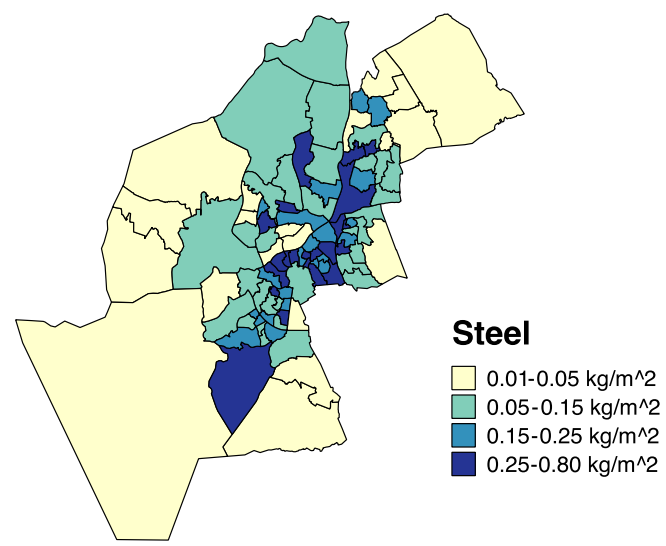

FIG URE 3 Density of material stock in $\mathrm{kg} / \mathrm{m}^{2}$ land area shown within the 96 neighborhoods of Gothenburg city. (a) Wood-based materials, brick and ceramics, and mineral-binding materials in buildings; (b) asphalt in road transportation; (c) steel in pipes. Note that material density location is dependent on built intensity in the area and other characteristics of the built environment components. Additional data provided in Supporting Information S2. A GIS shapefile, including codes for each neighborhood, is available for this figure in Supporting Information S3

\subsection{Spatial analysis of urban MS with clustering algorithm}

\subsubsection{MS and urban form}

The results shown in Figure 4 are based on the first set of indicators (see Section 2). The map indicates the spatial distribution of the formed clusters and the table below indicates the mean value corresponding to each indicator and cluster. Four neighborhood types were identified. Of the total urban area, neighborhood type I takes $25 \%$, type II takes $37 \%$, type III takes $36 \%$, and type IV takes $2 \%$.

Neighborhood type I is a SF residential area, which is spatially located on the coast (Figures 1 and 4). It has an average density of $140 \mathrm{~kg} / \mathrm{m}^{2}$. The buildings to roads ratio is $51 \%$ and buildings to pipes ratio is $2.1 \%$. Neighborhood type II is also a SF residential area, spatially distributed on the outskirts, but in-land (Figure 4). It has a higher density of $208 \mathrm{~kg} / \mathrm{m}^{2}$ and marginally lower ration of 49 and $1.9 \%$, respectively. Neighborhood type III is located in-between the central and the outskirts area (Figure 4). It is mainly residential (71\%) with a mix of SF and MF buildings. This typology has an average density of $435 \mathrm{~kg} / \mathrm{m}^{2}$, and a ratio of 27 and $1.2 \%$, respectively. Neighborhood type IV is centrally located (Figure 4). It has the highest mix of nonresidential and residential buildings. Moreover, this neighborhood type has the highest average stock density of $1,810 \mathrm{~kg} / \mathrm{m}^{2}$ and the lowest ratios of 11 and $0.6 \%$. These results suggest that a lower building density, such as SF residential areas, have proportionally higher MS in roads and pipes infrastructure networks. On the contrary, centrally located neighborhoods of mixed building types have a considerably higher MS density, and a lower proportion of MS in road and pipes infrastructure networks. Finally, it can be seen that the largest part of the city is built in low to medium MS density, and that only a small fraction is built in high density.

\subsubsection{MS composition in residential buildings}

The results shown in Figure 5 are based on the second set of indicators (see Section 2). Four neighborhood types were identified. In Figure 5, the results are shown spatially and the mean value of each indicator for the formed clusters is tabulated below. If cumulated, the stock for the four 
(a)

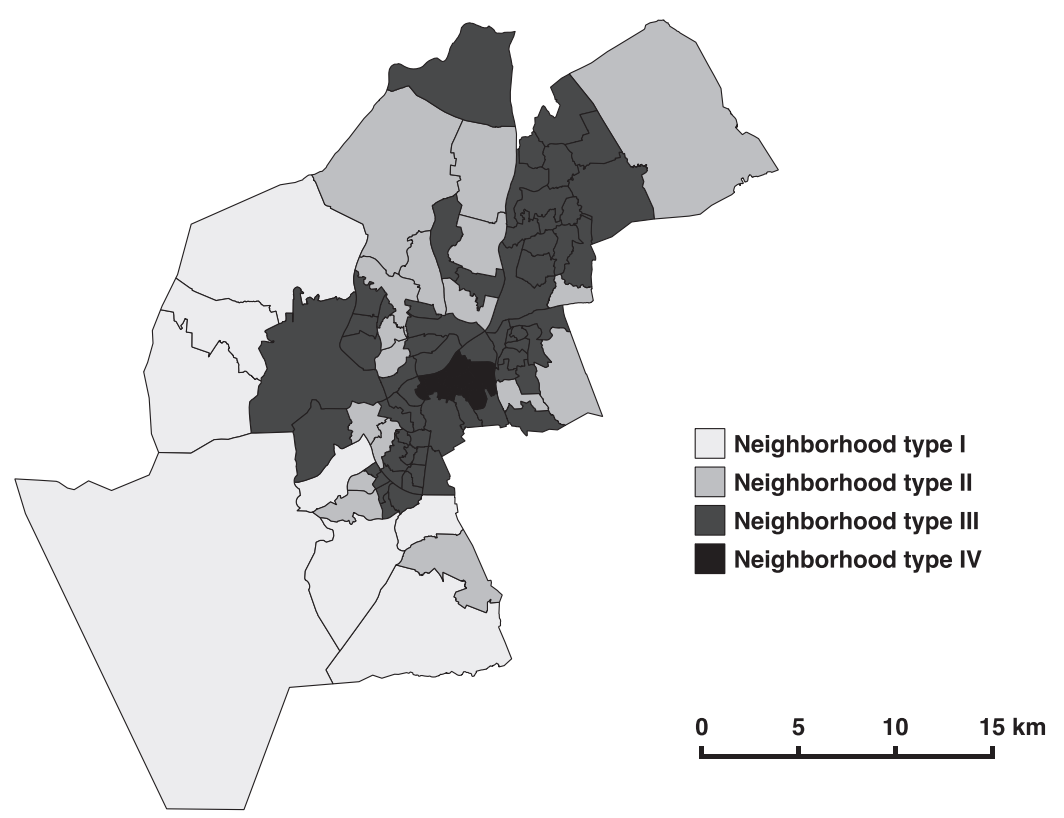

(b)

\begin{tabular}{lccccccc}
\hline & \multicolumn{3}{c}{ Material stock } & \multicolumn{2}{c}{ Building type } & \multicolumn{2}{c}{ Residential type } \\
& Buildings & Roads & Pipes & Residential & Non-residential & SF & MF \\
& {$\left[\mathrm{kg} / \mathrm{m}^{2}\right]$} & {$\left[\mathrm{kg} / \mathrm{m}^{2}\right]$} & {$\left[\mathrm{kg} / \mathrm{m}^{2}\right]$} & {$[\%]$} & {$[\%]$} & {$[\%]$} & {$[\%]$} \\
Type I & 91 & 46 & 1.8 & 94 & 6 & 98 & 2 \\
Type II & 136 & 69 & 2.9 & 89 & 11 & 96 & 4 \\
Type III & 340 & 92 & 4.2 & 71 & 29 & 61 & 39 \\
Type IV & 1632 & 171 & 9.4 & 56 & 44 & 2 & 98 \\
\hline
\end{tabular}

FIGURE 4 Clustering results for the first set of indicators. (a) Spatial representation; (b) tabulated values for each indicator and neighborhood type. SF, single-family residential buildings; MF, multifamily residential buildings. Additional data provided in Supporting Information S2

neighborhood types distributes as follows: 7.6 million tons for type A, 13.7 million tons for type B, 11.2 million tons for type $C$, and 1.6 million tons for type D.

Neighborhood type A is characterized by SF buildings and located at the outskirts of the city (Figure 5). Wood-based material accounts for $12 \%$ of the stock, which is the highest among the four neighborhood types and $56 \%$ is mineral-binding material. The buildings' ages are a mix of the three age-class intervals. Neighborhoods type B are characterized by MF buildings and are located in-between the outskirts and the central area (Figure 5). The stock is mainly composed of mineral-binding materials, which take circa $70 \%$ of the total. A total of $90 \%$ of the stock dates to $1951-$ 1980. Neighborhood type $C$ is, on the whole, MF built. In this case, the neighborhood cluster is centrally located (Figure 5 ) and $74 \%$ of the stock dates back to before 1950. Another particularity of this neighborhood cluster is the high brick and ceramics content (24\%), which is the largest of the four neighborhood types. Neighborhood type D is populated with 89\% MF buildings constructed mainly after the year 1981. Geographically, they are positioned in the center and intermediary areas of the city (Figure 5). A majority of the stock is made from mineral-binding materials (58\%), but the percentage of steel, at $17 \%$ of the residential MS, is noticeably high.

\section{4 | DISCUSSION}

\subsection{Discussion on the spatial analysis results}

With the first set of indicators, it was shown that low-density urban areas with SF residential buildings have a higher percentage of MS in transportation and pipes networks than higher-density mixed areas of nonresidential and MF residential buildings. These findings have implications for 
(a)

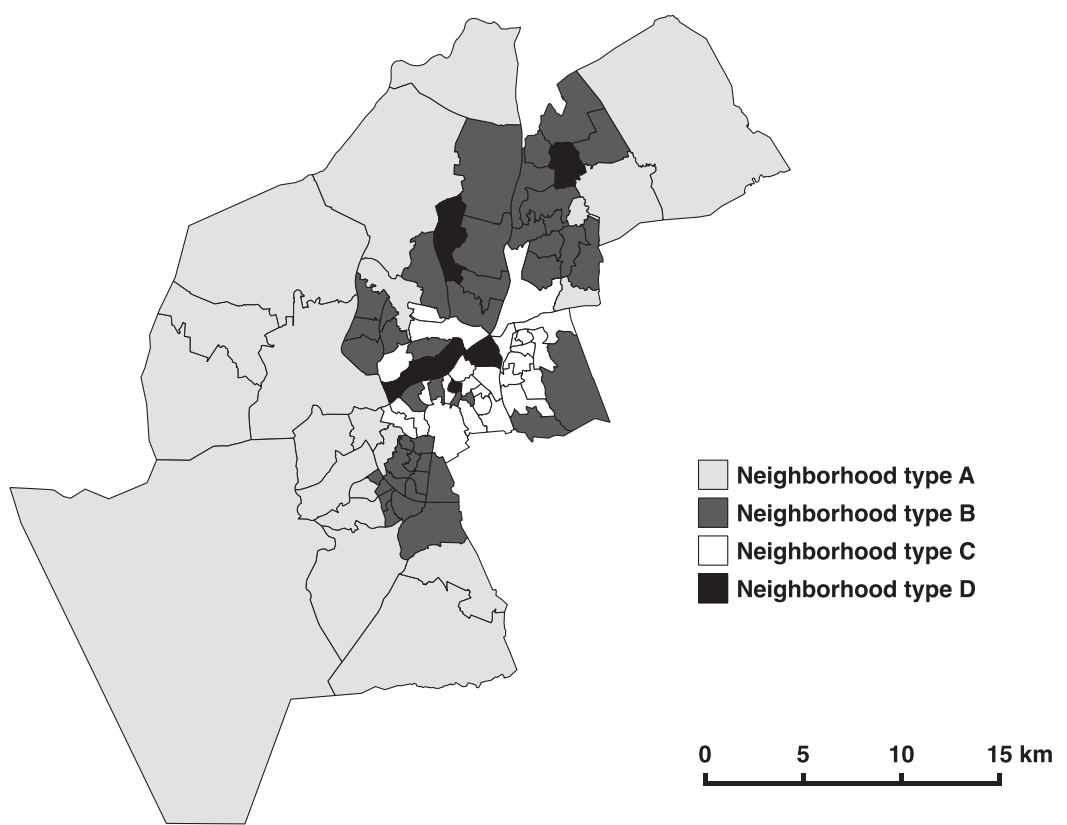

(b)

\begin{tabular}{lrrrrrrrrrrrr}
\hline & \multicolumn{4}{c}{ Material stock } & \multicolumn{3}{c}{ Residential type } & \multicolumn{3}{c}{ Age class } \\
& W & B & M & S & I & O & SF & MF & Before & $1951-$ & After \\
& & & & & & & & & 1950 & 1980 & 1981 \\
Type A & $12 \%$ & $5 \%$ & $56 \%$ & $8 \%$ & $11 \%$ & $8 \%$ & $90 \%$ & $10 \%$ & $25 \%$ & $43 \%$ & $32 \%$ \\
Type B & $4 \%$ & $7 \%$ & $70 \%$ & $2 \%$ & $12 \%$ & $5 \%$ & $10 \%$ & $90 \%$ & $5 \%$ & $89 \%$ & $6 \%$ \\
Type C & $9 \%$ & $24 \%$ & $44 \%$ & $7 \%$ & $9 \%$ & $7 \%$ & $11 \%$ & $89 \%$ & $74 \%$ & $16 \%$ & $10 \%$ \\
Type D & $5 \%$ & $11 \%$ & $58 \%$ & $3 \%$ & $17 \%$ & $6 \%$ & $11 \%$ & $89 \%$ & $14 \%$ & $15 \%$ & $71 \%$ \\
\hline
\end{tabular}

FIGURE 5 Clustering results for the second set of indicators applied to residential buildings. (a) Spatial representation; (b) tabulated values as percentages for each indicator and neighborhood type. W, wood-based material; B, brick and ceramics; M, mineral-binding materials; S, stone and aggregates; I, iron and steel; O, other construction materials. Additional data provided in Supporting Information S2

planning a less resource-intensive urban built environment, and could be especially relevant for the rapidly developing cities of the Global South (United Nations, 2014).

The topic of compact urban form is very complex and much debated in the literature (Burgess \& Jenks, 2002; Burton, Jenks, \& Williams, 2003; Jenks, 2000). Even though more compact cities show multiple benefits, such as efficient land use, effective public transportation, higher accessibility, and reduced car ownership, at the same time, the compact city shows a higher risk of pollution due to congestion, less open space, and less acceptance by some of the residents. These contradictions lead to conflicting solutions and questions are raised when discussing ways forward. Nevertheless, beyond tradeoffs, urban form remains one of the relevant factors of the urban-sustainability discourse. For instance, a recent study underlined the importance of the urban form in relation to climate change mitigation (Creutzig, Baiocchi, Bierkandt, Pichler, \& Seto, 2015). In a similar way, the current study showed variations in MS among diverse urban forms.

With the second set of indicators, neighborhoods that show specific material composition, age class, and building type were identified. Of the four clusters identified for residential buildings, one is SF residential and the three others are MF residential. Each of the neighborhood types has a specific material composition of wood, brick, mineral-binding and steel. Besides the material-composition specifics, it should be noted that SF buildings tend to cluster in a mix of different age classes from 1880 to 2010, whereas MF buildings tend to cluster in more distinctive age classes (before 1950,1951-1980, after 1981). Moreover, the age class suggests which construction materials to expect for secondary use when buildings come to an end of their lifetime. The end of life of buildings is nevertheless a very complex matter, and in most cases the designed lifetime is not an appropriate indicator. For instance, in the case of China, it was shown that internal factors (e.g., construction quality, building type, etc.) have much less influence over the end of life of buildings when compared to external factors such as the economic context (Liu, Xu, Zhang, \& Zhang, 2014). The 
end of life of buildings in the context of the present case study was not researched, and to make further use of the present results future analysis on this topic is needed.

\subsection{Discussion on the spatial analysis approach}

k-mean clustering algorithm was employed for the present study. To test if a different clustering algorithm leads to different results, hierarchical clustering (Murtagh, 1985) and k-median clustering (Cardot et al., 2012) were applied to the second set of indicators (see Section 2). Hierarchical clustering returned similar results to k-mean clustering (Figure S1 in Supporting Information S1). However, five neighborhoods changed to a different cluster. The reasons for changing to another cluster were threefold: (a) the values for all the indicators were in-between the formed clusters, (b) some indicators were strongly related with one cluster whereas the others were strongly related to the other cluster, or (c) the indicators were not common to any of the formed clusters. It was not possible to clearly locate the five neighborhoods in a particular cluster and they, therefore, can be considered outliers. k-median clustering returned considerably different results from k-mean clustering. Even though neighborhood types A, B, and C maintained their characteristics, neighborhood type D did not. Instead, $k$-median identified a new cluster that had different characteristics (Figure S2 in Supporting Information S1). This optimization was carried out the expense of increased distortion in cluster D and the other clusters (Table S3 in Supporting Information S1). Moreover, on multiple runs of the $k$-median algorithm, the returned results were less stable than those returned with the other two algorithms. Nonetheless, these results also point to the fact that neighborhood type $D$ is a weak cluster formation.

It can be concluded that testing multiple algorithms was useful to identify outliers that do not fit into any of the formed clusters. This outcome also suggests that the trends underlined with the proposed spatial-analysis approach are representative only for the entire city, and not representative for each individual neighborhood. Furthermore, it was possible to identify the weak clusters such as neighborhood type D. Finally, these analyses indicate that different algorithms can return different results and, therefore, further analysis on algorithms and their impact on spatial analysis of urban MS are recommended.

Low variations in the indicators among the neighborhoods showed less categorical patterns. This was showcased with nonresidential buildings (Figure S3 in Supporting Information S3), which like residential buildings were clustered with the second set of indicators (see Section 2). The results indicate that nonresidential buildings are more homogenously distributed compared to residential buildings. In this case, a smaller spatial segmentation could be more appropriate for the analysis. Moreover, nonresidential buildings showed less distinctive materialintensity coefficients in comparison to the residential buildings (Table 1) and, therefore, less distinctive material-composition patterns could be depicted.

The spatial analysis method can only be applied to bottom-up MS studies with rich spatial data. Rich spatial data are not available in many parts of the world, and this can be a limitation for future application of the proposed approach. Nevertheless, spatial data availability worldwide tends to increase in both quantity and quality. Furthermore, material-intensity databases have not yet been developed in many countries, which could further limit the application of the proposed method.

The neighborhood boundaries were used to capture the characteristics of different urban areas. For replicability purposes, it is important that subcity boundaries are common in other cities around the world. In the European Union (EU) all the cities above 250,000 inhabitants should have defined subcity administrative boundaries (Eurostat 2017; Urban Audit, 2004). Urban Audit (2004) has suggested three main criteria for defining the boundaries, namely the cities should have between 5,000 and 40,000 residents depending on the city size, should be internally homogenous in terms of social structure and built environment, and should show contrasting differences to the other neighborhoods. A short screening of the main webpage of several cities worldwide indicates that subcity boundaries are common, but, nonetheless, collective reports on this matter, as in the case of the EU, were not found. An alternative spatial segmentation method is the use of standardized grid cells, which have been previously reported on in the literature and are available worldwide.

The reason for selecting the 96 neighborhoods for the present study was partly because they follow the EU criteria; partly because socioeconomic and demographic indicators (e.g., car ownership, income, etc.) is openly available within these spatial boundaries and it could determine further analysis of the urban MS. For instance, SF residential areas that in this study were found to have a higher proportion of road MS, also have 59\% higher car ownership than in MF residential areas (418 cars/1,000 inhabitants for SF and 263 cars/1,000 inhabitants for MF) (Statistics Gothenburg, 2016b). From a material resource point of view, the car ownership indicator further supports the concept of a more compact urban form. Further studies could look at correlations between average income, demographical indicators, and MS accumulation. Such analysis could contribute to the discussion on drivers of MS accumulation (Fishman et al., 2015; Huang et al., 2016), and complement this topic from the household perspective in relation to urban form.

\subsection{MS per capita}

MS per capita is a commonly used indicator to compare and partly validate results in MS studies. Even though the stock in residential buildings and road networks in EU 25 (Wiedenhofer et al., 2015) and pipes in European cities (Pauliuk, Venkatesh, Brattebø, \& Müller, 2014) have been looked 
TAB LE 3 Material stock per capita from current and previous case studies

\begin{tabular}{|c|c|c|c|c|c|c|c|}
\hline Case study & Total & Buildings & Residentials & Roads & Wastewater & Year & Source \\
\hline Beijing, China & $a_{-}$ & 38 & 16 & 1 & 2.3 & 2013 & Huang et al. (2016) \\
\hline beijing, China & - & - & - & 6 & - & 2013 & Guo et al. (2014) \\
\hline Chiclayo, Peru & - & - & 55 & - & - & 2016 & Mesta et al. (2018) \\
\hline Gothenburg, Sweden & c153 & 112 & 62 & 38 & 1.3 & 2016 & Current study \\
\hline dManchester, UK & - & 79 & 38 & 24 & - & 2004 & Tanikawa and Hashimoto (2009) \\
\hline Oslo, Norway & - & - & - & - & 0.9 & 2008 & Pauliuk et al. (2014) \\
\hline Shanghai, China & - & 39 & 24 & 0.9 & 2.9 & 2013 & Huang et al. (2016) \\
\hline Tianjin, China & - & 54 & 25 & 2.3 & 4.4 & 2013 & Huang et al. (2016) \\
\hline Trondheim, Norway & - & - & - & - & 1.0 & 2008 & Pauliuk et al. (2014) \\
\hline Vienna, Austria & - & 210 & 132 & - & - & 2013 & Kleemann et al. (2016) \\
\hline dWakayama, Japan & - & 221 & 108 & 26 & - & 2004 & Tanikawa and Hashimoto (2009) \\
\hline EU 25 countries & - & - & 72 & 80 & - & 2009 & Wiedenhofer et al. (2015) \\
\hline Industrialized countries & e 335 & - & - & - & - & 2010 & Krausmann et al. (2017) \\
\hline
\end{tabular}

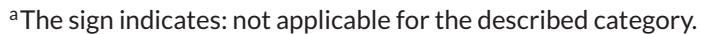

${ }^{b}$ The values were calculated as $80 \%$ of the total road stock, without the $20 \%$ ancillary facilities.

'The value refers to material stock accumulated in buildings, road transportation, and water pipes.

${ }^{\mathrm{d}}$ The stock was calculated for central areas in the two cities.

e The value refers to the material stock accumulated in buildings, infrastructures, and durable goods.

at previously, the present work is the first bottom-up MS study of a Northern European city. Therefore, the results of the current study are further contrasted with those from previous case studies (Table 3).

The per capita stock for industrial countries was estimated at $335 \mathrm{t}$ (Krausmann et al., 2017), which is circa twice as high as the $153 \mathrm{t}$ shown for the present case study. The difference can be partly explained by the fact that the referenced article included all the infrastructure types and the durable goods, which were not considered in the current assessment. Previous studies have shown that some infrastructures could make a considerable contribution to the stock. For example, seaports, in the case of Japan, showed a contribution of 19\% to the overall stock (Tanikawa et al., 2015). Furthermore, it was shown that top-down MS estimates tend to be higher when compared to the bottom-up MS estimates (Tanikawa et al., 2015). This aspect could further explain the different findings.

Residential stock per capita for Gothenburg was estimated at $62 \mathrm{t}$ (Table 3). Similar values (13\% lower) were shown for the city of Chiclayo in Peru, which, as of 2016, had residential stock estimated at $55 \mathrm{t}$ per capita (Mesta et al., 2018). The three largest Chinese cities had two to three times lower residential stock per capita: $16 \mathrm{t}$ for Beijing and $25 \mathrm{t}$ for Tianjin (Huang et al., 2016). The level of economic development can explain the lower stock in these case studies. However, this argument is not valid for Manchester city, which shows a residential stock of $38 \mathrm{t}$ per capita (Tanikawa \& Hashimoto, 2009). The study of the EU 25 countries (Wiedenhofer et al., 2015) showed a residential stock per capita of $72 \mathrm{t}$, which, to a certain extent, validates the results of the present study. The relatively higher stock can be explained by the high number of SF residential areas in the EU 25, which have a higher stock per capita than MF building areas. Moreover, the difference can also be explained by the brick and concrete structure of SF buildings, which are predominant in the EU 25 (Wiedenhofer et al., 2015), contrasted to the mainly wooden structure SF in Sweden (Gontia et al., 2018). In contrast, other studies showed larger residential stock per capita. For instance, for Vienna, Austria, the residential stock was estimated at $131 \mathrm{t}$ (Kleemann et al., 2016) and for the city center of Wakayama, Japan the residential stock was estimated at $108 \mathrm{t}$ (Tanikawa \& Hashimoto, 2009). Some possible explanations for the case of Japan could be the national regulations due to seismic activities, which, consequently, have led to higher material intensity (Tanikawa \& Hashimoto, 2009). In the case of Vienna, the considerably higher stock can be partly explained by the $15 \%$ higher material-intensity coefficients when compared to those used in the present study (Gontia et al., 2018).

For the road network, the current study showed, on average, higher stock per capita than other case studies (Table 3). For instance, it is $45 \%$ higher compared to the center of Wakayama, Japan and 58\% higher compared to Manchester, UK (Tanikawa \& Hashimoto, 2009). A large difference (up to 40 times higher) can be seen in comparison to the Chinese cities (Huang et al., 2016). However, the difference might be actually smaller as indicated by another study, which for Beijing estimated the road stock per capita to $6 \mathrm{t}$ (Guo et al., 2014). The study of the EU 25 countries showed a stock in roads of circa $80 \mathrm{t}$ per capita (Wiedenhofer et al., 2015), which is twice as high as the figure estimated in the current study. Further investigations are necessary for the Chinese cities, but the underlined differences in stock for the road network can be speculatively explained by the population density. Thus, lower population density indicates a higher road stock per capita. In the current context, the population density for the EU 25, as of 2003, was 118 inhabitants $/ \mathrm{km}^{2}$ (Eurostat 2006), Gothenburg has a population density of 1,260 inhabitants/km², and the city center of Wakayama, Japan, as of 2009 had a density of 4,500 inhabitants $/ \mathrm{km}^{2}$ (Tanikawa \& Hashimoto, 2009). For the wastewater pipes, 
the Chinese cities showed two to three times higher values in comparison to the current study (Huang et al., 2016). Nonetheless, other European cities (Pauliuk et al., 2014) showed similar results to Gothenburg at circa 1 ton per capita (Table 3).

\section{5 | CONCLUSIONS AND FUTURE WORK}

In this article, an innovative approach to spatially analyze urban MS was introduced. The main scope of these analyses was to identify areas in the urban geography that have similar MS characteristics. For this purpose, MS indicators were defined at neighborhood level and clustered with $k$ mean algorithms. Bottom-up estimations of MS for three built environment components were created: buildings, road transportation, and pipes. Gothenburg, Sweden with its 96 neighborhoods was used as a case study. Since, this was the first case study for Northern Europe, the results were explored from a variety of angles and contrasted on a per capita basis to other studies worldwide.

In-use MS was estimated at circa 84 million t. Buildings take $73 \%$ of the stock, road transport $26 \%$, and pipes $1 \%$. Mineral-binding materials account for the largest share of the stock, followed by aggregates, brick, asphalt, steel, and wood. The largest part of the stock comes from the period interval 1960-1980. The estimated MS per capita equals to $153 \mathrm{t}$. The residential stock was determined at $62 \mathrm{t}$ per capita, which is between the lowest and the highest values found in previous studies. Spatially, it was demonstrated that dense built neighborhoods of mixed residential and nonresidential buildings have a lower proportion of MS in roads and pipes, than low-density SF residential neighborhoods. Furthermore, residential buildings have distinct spatial patterns in material composition. Whereas SF residential neighborhoods tend to cluster in mixed-age classes and have a considerably higher wood composition, MF residential neighborhoods tend to cluster in single-age classes with distinct material compositions of brick, mineral binding, and steel.

Further methodological work should be undertaken on developing MS indicators, testing other spatial divisions of urban stock, and contrasting different clustering algorithms. In terms of possible case studies, it would be interesting to apply the proposed spatial-analysis approach to megacities or multiple cities.

\section{ACKNOWLEDGMENTS}

This work has been financially supported by Mistra Urban Futures, Formas, and Chalmers Area of Advance Liveable Cities. The authors would like to thank Jakob Ljungquist for supplying this work with the spatial data on pipe infrastructures. Finally, we would like to thank the journal editors and anonymous reviewers for their valuable comments.

\section{CONFLICT OF INTEREST}

The authors declare no conflict of interest.

\section{ORCID}

Paul Gontia (D) https://orcid.org/0000-0002-2364-3485

Babak Ebrahimi (D) https://orcid.org/0000-0002-3086-0816

\section{REFERENCES}

Augiseau, V., \& Barles, S. (2017). Studying construction materials flows and stock: A review. Resources, Conservation and Recycling, 123(Supplement C), 153164.

Boverket. (2014). Under miljonprogrammet byggdes en miljon bostäder. Karlskrona, Sweden: Boverket. Retrieved from www.boverket.se/sv/samhallsplanering/ stadsutveckling/miljonprogrammet

Burgess, R., \& Jenks, M. (2002). Compact cities: Sustainable urban forms for developing countries. Abingdon, UK: Routledge.

Burton, E., Jenks, M., \& Williams, K. (2003). The compact city: A sustainable urban form? Abingdon, UK: Routledge.

Cardot, H., Cénac, P., \& Monnez, J.-M. (2012). A fast and recursive algorithm for clustering large datasets with k-medians. Computational Statistics Data Analysis, 56(6), 1434-1449.

Creutzig, F., Baiocchi, G., Bierkandt, R., Pichler, P. P., \& Seto, K. C. (2015). Global typology of urban energy use and potentials for an urbanization mitigation wedge. Proceedings of the National Academy of Sciences of the United States of America, 112(20), 6283-6288.

Eurostat. (2006). Population Statistics. Luxembourg: Eurostat.

Eurostat. (2017). Methodological manual on city statistics. Luxembourg: Eurostat.

Fischer-Kowalski, M., Swilling, M., von Weizsäcker, E. U., Ren, Y., Moriguchi, Y., Crane, W., ... Sewerin, S. (2011). Decoupling natural resource use and environmental impacts from economic growth. Nairobi, Kenya: United Nations Environmental Programme.

Fishman, T., Schandl, H., \& Tanikawa, H. (2015). The socio-economic drivers of material stock accumulation in Japan's prefectures. Ecological Economics, 113, 76-84. 
Fishman, T., Schandl, H., \& Tanikawa, H. (2016). Stochastic analysis and forecasts of the patterns of speed, acceleration, and levels of material stock accumulation in society. Environmental Science and Technology, 50(7), 3729-3737.

Fishman, T., Schandl, H., Tanikawa, H., Walker, P., \& Krausmann, F. (2014). Accounting for the material stock of nations. Journal of Industrial Ecology, 18(3), 407-420.

Gontia, P., Nägeli, C., Rosado, L., Kalmykova, Y., \& Österbring, M. (2018). Material-intensity database of residential buildings: A case-study of Sweden in the international context. Resources, Conservation and Recycling, 130, 228-239.

Guo, Z., Hu, D., Zhang, F., Huang, G., \& Xiao, Q. (2014). An integrated material metabolism model for stocks of urban road system in Beijing, China. Science of the Total Environment, 470, 883-894.

Han, J., \& Xiang, W. N. (2013). Analysis of material stock accumulation in China's infrastructure and its regional disparity. Sustainability Science, 8(4), 553-564.

Han, J., Chen, W.-Q., Zhang, L., \& Liu, G. 2018. Uncovering the spatiotemporal dynamics of urban infrastructure development: A high spatial resolution material stock and flow analysis. Environmental Science and Technology, 52(21), 12122-12132.

Hartigan, J. A., \& Wong, M. A. (1979). Algorithm AS 136: A k-means clustering algorithm. Journal of the Royal Statistical Society. Series C (Applied Statistics), 28(1), 100-108.

Huang, C., Han, J., \& Chen, W.-Q. (2016). Changing patterns and determinants of infrastructures' material stocks in Chinese cities. Resources, Conservation and Recycling, 123, 47-53.

Jenks, M. (2000). Achieving sustainable urban form. Abingdon, UK: Taylor \& Francis.

Kleemann, F., Lederer, J., Rechberger, H., \& Fellner, J. (2016). GIS-based analysis of Vienna's material stock in buildings. Journal of Industrial Ecology, 21, 368380.

Krausmann, F., Wiedenhofer, D., Lauk, C., Haas, W., Tanikawa, H., Fishman, T., ... Haberl, H. (2017). Global socioeconomic material stocks rise 23-fold over the 20th century and require half of annual resource use. Proceedings of the National Academy of Sciences, 114(8), 1880-1885.

Goteborg Stad. (2018). Kretslopp och Vatten. Gothenburg, Sweden: Goteborg Stad. Retrieved from http://goteborg.se/wps/portal/start/kommun-o-politik/ kommunens-organisation/forvaltningar/forvaltningar/forvaltningen-kretslopp-och-vatten/!ut/p/z1/hY7LCslwFES_ptvc29g2ibtQpFBfG6E1G2klpoWSKMBv966FBRnN8wZZkBBCWqoHq2pXDsOVbf4sOouEcOwzKNwm20kQxmnNN4fjqvOhFD8A9QS4w9JhBxUW_fEX3uChNKYccqF4CzilhHsvS-Hes UNKKtv2mpL7na51Tg3zesAA_TeEzOOptNk1gF-azTj7KD8AGHqy-dOF_IFaaObVw!!/dz/d5/L2dBISEvZOFBIS9nQSEh/

Lantmäteriet. (2018). Gävle, Sweden: Lantmäteriet. Retrieved from https://www.lantmateriet.se/

Liu, G., Xu, K., Zhang, X., \& Zhang, G. (2014). Factors influencing the service lifespan of buildings: An improved hedonic model. Habitat International, 43, 274282.

Malm, A., Horstmark, A., Larsson, G., Uusijärvi, J., Meyer, A., \& Jansson, E. (2011). Pipe material in Swedish water-and sewer pipelines- Characteristics and life-time expectations [in Swedish]. Stockholm, Sweden: Svensk Vatten AB.

Mesta, C., Kahhat, R., \& Santa-Cruz, S. (2018). Geospatial characterization of material stock in the residential sector of a latin-American city. Journal of Industrial Ecology, 23, 280-291.

Mirzanamadi, R., Hagentoft, C.-E., Johansson, P., \& Johnsson, J. (2018b). Anti-icing of road surfaces using hydronic heating pavement with low temperature. Cold regions science and technology, 145, 106-118.

Mirzanamadi, R., Johansson, P., \& Grammatikos, S. A. (2018a). Thermal properties of asphalt concrete: A numerical and experimental study. Construction and Building Materials, 158, 774-785.

Murtagh, F. (1985). Multidimensional clustering algorithms. Vienna, Austria: Physika Verlag.

Nguyen, T. C., Fishman, T., Miatto, A., \& Tanikawa, H. (2018). Estimating the material stock of roads: The Vietnamese case study. Journal of Industrial Ecology, 23, 663-673.

Ortlepp, R., Gruhler, K., \& Schiller, G. (2015). Material stocks in Germany's non-domestic buildings: A new quantification method. Building Research and Information, 44, 840-862.

Pauliuk, S., Venkatesh, G., Brattebø, H., \& Müller, D. B. (2014). Exploring urban mines: Pipe length and material stocks in urban water and wastewater networks. Urban Water Journal, 11(4), 274-283.

Pipelife Sverige AB. (2000). Handbook for PE pipes. Ölsremma, Sweden: Pipelife Sverige AB.

QGIS Geographic Information System. (2018). Open source geospatial foundation project. Beaverton, OR: QGIS Geographic Information System.

Reyna, J. L., \& Chester, M. V. (2015). The growth of urban building stock: Unintended lock-in and embedded environmental effects. Journal of Industrial Ecology, 19(4), 524-537.

Schiller, G. (2007). Urban infrastructure: Challenges for resource efficiency in the building stock. J Building Research Information, 35(4), 399-411.

Goteborg Stad. Stadsbyggnadskontoret. (2018). Gothenburg, Sweden: Goteborg Stad. Retrieved from http://goteborg.se/wps/portal/start/kommun-opolitik/kommunens-organisation/forvaltningar/forvaltningar/stadsbyggnadskontoret/!ut/p/z1/hY7LCslwFES_ptvc29g2ibsgUqhacdWajbQSO0JfpNGA X29dCoqzG-YMM6CgBDVUj9ZUrh2Hqlv8WSWXiKYYZIG4S7eSoYw3ND7kx9UpD6H4B6glxh-SCBmotu6Jv_YECaUx45QLwVnERSLYe18O9YobUFb ftNWW301yq3FumtcBBui9J2YcTafJrAP81mjG2UH5AcLUI8-9LuQL1Svo2w!!/dz/d5/L2dBISEvZOFBIS9nQSEh/

Statistics Gothenburg. (2016a). Befolknings utveckling [Population growth]. Gothenburg, Sweden: Statistics Gothenburg.

Statistics Gothenburg. (2016b). Socio-economic statistics at district level 2016. Gothenburg, Sweden: Statistics Gothenburg. Retrieved from http://statistik. goteborg.se/Statistik/Faktablad/Goteborgsbladet/Goteborgsbladet-2016/

Statistics Gothenburg. (2018a). Administrative division: History 1900-2018. Gothenburg, Sweden: Statistics Gothenburg. Retrieved from http://statistik. goteborg.se/Omradesindelning/Indelningar/Historik-primaromraden/

Statistics Gothenburg. (2018b). Geographycal divisions. Gothenburg, Sweden: Statistics Gothenburg. Retrieved from http://statistik.goteborg.se/Omrades indelning/Indelningar/

Tanikawa, H., Fishman, T., Okuoka, K., \& Sugimoto, K. (2015). The weight of society over time and space: A comprehensive account of the construction material stock of Japan, 1945-2010. Journal of Industrial Ecology, 19(5), 778-791.

Tanikawa, H., \& Hashimoto, S. (2009). Urban stock over time: Spatial material stock analysis using 4d-GIS. Building Research and Information, 37(5-6), 483-502.

Tibshirani, R., Walther, G., \& Hastie, T. J. J. o. t. R. S. S. S. B. 2001. Estimating the number of clusters in a data set via the gap statistic. 63(2): 411-423.

Trafikverket. (2018). National road database. https://www.trafikverket.se/tjanster/system-och-verktyg/data/Nationell-vagdatabas/. Accessed 2018.

United Nations. (2014). World Urbanization Prospects. Francisco, California: United Nations.

Urban Audit. (2004). Methodological Handbook. Brussels, Belgium: Urban Audit. 
Wiedenhofer, D., Steinberger, J. K., Eisenmenger, N., \& Haas, W. (2015). Maintenance and expansion: Modeling material stocks and flows for residential buildings and transportation networks in the EU25. Journal of Industrial Ecology, 19(4), 538-551.

\section{SUPPORTING INFORMATION}

Additional supporting information may be found online in the Supporting Information section at the end of the article.

How to cite this article: Gontia P, Thuvander L, Ebrahimi B, Vinas V, Rosado L, Wallbaum H. Spatial analysis of urban material stock with clustering algorithms: A Northern European case study. J Ind Ecol. 2019;1-16. https://doi.org/10.1111/jiec.12939 